\title{
CORRECTION
}

\section{Correction to: Anticancer potential of metformin: focusing on gastrointestinal cancers}

\author{
${\text { Mohammad rafi Khezri }{ }^{1} \cdot \text { Hassan Malekinejad }}^{1,2}\left[\right.$ (]) Naime Majidi-Zolbanin ${ }^{1,2} \cdot$ Morteza Ghasemnejad-Berenji $^{1,2}$ (1)
}

Published online: 2 August 2021

(c) Springer-Verlag GmbH Germany, part of Springer Nature 2021

\section{Correction to: \\ Cancer Chemotherapy and Pharmacology \\ (2021) 87:587-598}

https://doi.org/10.1007/s00280-021-04256-8

In the original publication of the article, the family name of the corresponding author has been misspelled as Melekinejad. However, the corrected form is "Malekinejad".

The original article has been corrected.

Publisher's Note Springer Nature remains neutral with regard to jurisdictional claims in published maps and institutional affiliations.

The original article can be found online at https://doi.org/10.1007/ s00280-021-04256-8.

Hassan Malekinejad

malekinejad.h@umsu.ac.ir

$\triangle$ Morteza Ghasemnejad-Berenji

ghasemnejad.m@umsu.ac.ir

1 Department of Pharmacology and Toxicology, Faculty of Pharmacy, Urmia University of Medical Sciences, PO Box: 5715799313, Urmia, Iran

2 Experimental and Applied Pharmaceutical Sciences Research Center, Urmia University of Medical Sciences, Urmia, Iran 